\title{
ROLE OF MAGNATIC RESONANCE IMAGING (MRI) IN THE PRE-OPERATIVE DIAGNOSIS OF LUMBAR DISC HERNIATION
}

\author{
KAMAL F ${ }^{1}$, QUDDUS MA ${ }^{2}$, HOSSAIN A ${ }^{3}$, RAHMAN MM ${ }^{4}$, SARKAR RN ${ }^{4}$, NABI $\mathrm{S}^{4}$, AHMED $\mathrm{S}^{4}$, \\ CHOWDHURY N ${ }^{4}$, RAHMAN $\mathrm{K}^{4}$
}

\begin{abstract}
Objectives: To diagnose lumbar disc herniation by MRI, to compare the MRI findings with peroperative findings and to elucidate validity of MRI in pre-operative diagnosis of lumbar disc herniation.

Methodology:The study was done between January 2008 to March 2009 with 40 patients (28 male and 12 female) who were clinically suspected as cases of lumbar disc herniation and was referred for MRI of Lumbo-sacral spine to the Radiology and Imaging department of Dhaka Medical College Hospital. Detail history, clinical examination and MRI of lumbo-sacral spine were performed in all cases and the Patients were followed up during the surgery. The peroperative findings were then correlated with MRI findings and for the validity of the study outcome, sensitivity, specificity, accuracy, positive predictive value and negative predictive values of MRI in the diagnosis of Lumbar disc herniation were calculated.

Results: In this study 21(52.5\%) cases were found in $3^{\text {rd }}$ decade, 17(42.5\%) cases in the $4^{\text {th }}$ decade and 2 (5.0\%) cases in $5^{\text {th }}$ decade. Male female ratio of lumbar disc herniation is 2.33:1 (28:12). 60\% of the study subjects were stressful and that of $40 \%$ was sedentary. Lumber disc herniation was mostly seen at L4-5 level (57.5\%) and L5-S1 level (25\%). MRI was 94.28\% sensitive, 60\% specific and showed an accuracy of $90 \%$.

Conclusion: This study established the use of MRI as the radiological investigation for detection of lumbar disc herniation. The procedure is safe and cost effective.
\end{abstract}

Key words: Lumbar Disc Herniation, Magnatic Resonance Imaging (MRI).

J Dhaka Med Coll. 2009; 18(1) : 8-14

\section{Introduction}

Low back pain belongs to one of the most common sufferings observed in mankind and can lead to serious limitation of activity. ${ }^{1}$ Lumbar disc herniation is an important cause of low back pain with sciatica ${ }^{2}$. Herniation is defined as a localized displacement of disc material beyond the limits of the intervertebral disc space ${ }^{3}$.A symptomatic lumbar disc herniation occurs during the life time of approximately $2 \%$ of the population. Risk factors include male gender, age (30-50 years), heavy lifting or twisting and stressful occupation. Over $90 \%$ disc herniations occur at the level of L4-5 or L5-S14.Symptoms typically commence with a period of back pain followed by sciatica. There may be paraesthesia, motor weakness, loss of reflexes and reduction in straight leg raise. A large midline disc herniation may compress the cauda equina laeding to cauda equina syndrome defined by bowel and/or bladder difficulties, saddle anaesthesia and lower limb sensory and motor deficits. Previous experience indicates that MRI can identify lumbar canal stenosis and herniated nucleus pulposus ${ }^{5}$. The accuracy of MRI for predicting the presence of disc herniation at surgery is relatively high (varying from 76 to $96 \%)^{6}$.Thus

1. Department of Radiology \& Imaging, Dhaka Medical College Hospital, Dhaka.

2. Professor and Head, Department of Radiology \& Imaging, Dhaka Medical College \& Hospital, Dhaka.

3. Ex-Professor, Department of Radiology \& Imaging, Dhaka Medical College \& Hospital, Dhaka.

4. Assistant Professor, Department of Radiology \& Imaging, Dhaka Medical College \& Hospital, Dhaka.

Correspondence: Dr. Farhana Kamal Kumu 
it has become the choice of investigations for imaging lower back and lower extremity radiculitis in patients suspected of lumber disc herniation.

From Radiological point of view, In Bangladesh only a very few studies have been done on pre-operative diagnosis of lumbar disc herniation by MRI. As such exact data on the validity of MRI in the diagnosis of lumbar disc herniation is not available. The purpose of this study was to diagnose lumbar disc herniation by MRI, compare the MRI findings with per-operative findings and to elucidate validity of MRI in pre-operative diagnosis of lumbar disc herniation.

\section{Materials and Methods:}

This cross sectional study was carried out between January 2008 to March 2009 in patients who were clinically suspected as cases of lumbar disc herniation and was referred for MRI of lumbar spine examination. Selected 40 cases (28 male and 12 female) were evaluated in the department of Radiology and Imaging of Dhaka Medical College Hospital (DMCH), Dhaka. The study was carried out in collaboration with department of orthopedic surgery, $\mathrm{DMCH}$ and Spine surgery unit, department of orthopedic surgery, Bangabandhu Sheikh Mujib Medical University (BSMMU), Dhaka. Patients having clinical features of Lumbar Disc Herniation were included in the study. Patients who refused to undergo surgery or in Cases where operation note was not available and Patients having any kind of metallic prosthesis not compatible for MRI were excluded from the study.

All the patients were evaluated by detail history and clinical examination with special emphasis on clinical features. Subsequently MRI of lumbosacral spine was performed in all cases by a 0.3 Tesla open MRI machine. Images were taken at saggital and axial sections at spin echo (SE) sequences in T1-weighted and fast spin echo (FSE) sequence in T2-weighted images using slice thickness of $05 \mathrm{~mm}$ and intersection gap of $06 \mathrm{~mm}$ and with variable matrix size.

\section{Diagnostic criteria: ${ }^{7}$}

Protrusion-It is a herniated disc with broad base at parent disc. Greatest dimension of disc herniation in plane is d" distance between edges of the base in same plane.

Extrusion- It is a herniated disc with narrow or no base at parent disc. Greatest dimension of disc herniation in plane is >distance between edges of the base in same plane.

Sequestrated / Free fragment- Extruded disc without continuity to parent disc. The disc material may migrate away from the site of herniation.

Bulging disc: ${ }^{8} A$ bulging disc represents a disc herniation that extends diffusely beyond the vertebral body margins in all directions. The MR appearance of disc bulging is symmetric uniform extension of the outer disc margin circumferentially. Lumbar disc herniation is most common at L4-5 or L5-S1. There may be loss of disc height, degenerative changes. On T1WI disc is iso-intense to parent disc. On T2WI disc is iso to hypo- intense, depending on disc hydration. There may be variable extent of nerve impingement. Virtually all lumbar herniation are associated with degeneration of the intervertebral portion of the disc on T1-weighted images. The loss of signal intensity reflecting disc degeneration is more apparent on T2 weighted SE images. The hallmark of a herniated disc is a focal contour abnormality along the posterior disc margin with a soft tissue mass displacing the epidural fat, nerve root, epidural veins, or thecal sac. Herniated disc typically have very low signal intensity on sagittal and axial T2 weighted FSE images Nerve root and thecal sac compression are well shown on $\mathrm{T} 1$ weighted SE images in axial plane. 


\section{Per-operative correlation:}

Patients were observed during operation. Operative findings and diagnosis were noted down and correlated with MRI findings and diagnosis.

Data collection and statistical analysis of data: For the validity of the study outcome, sensitivity, specificity, accuracy, positive predictive value and negative predictive value of MRI in the diagnosis of Lumbar disc herniation were calculated out after confirmation of the diagnosis by operation.

\section{Results and Observations:}

In the study highest incidents of lumbar disc herniation were found in the 3rd decade of life occurring in $21(52.5 \%)$ cases, Followed by $4^{\text {th }}$ decade occurring in $17(42.5 \%)$ cases and in 5 th decade $2(5 \%)$ cases.

The sex incidence of lumbar disc herniation was $28(70 \%)$ in male and $12(30 \%)$ in female.

The incidence of lumber disc herniation was $60 \%$ in manual workers and $40 \%$ in sedentary workers.

Regarding the symptoms, multiple responses were found in single patient.

The most common and constant presentation was low back pain found in 40 (100\%) cases, Pain radiating to lower limb was present in 35 $(87.5 \%)$ cases, Restricted SLR were found in $33(82.5 \%)$ cases along with Low back pain. Motor Involvement was present in 34 (85\%) cases. Sensory involvement was found in 31 $(77.5 \%)$ cases. Bowel \& bladder involvement was found in 07 (17.5\%).

Table -I

Showing the frequency of Level of discherniation ( $n=40$ )

Level of Disc Frequency Percentage

Herniation

\begin{tabular}{lcc}
\hline L4-L5 & 23 & 57.5 \\
L5-S1 & 10 & 25 \\
Both L4-L5 \& L5-S1 & 07 & 17.5 \\
\hline TOTAL & 40 & 100 \\
\hline
\end{tabular}

Table-II Preoperative MRI findings ( $n=40$ )

\begin{tabular}{lcc}
\hline $\begin{array}{l}\text { Pre-operative } \\
\text { MRI findings }\end{array}$ & Frequency & Percentage \\
\hline $\begin{array}{l}\text { Lumbar disc } \\
\text { herniation only }\end{array}$ & 35 & 87.5 \\
Spinal Stenosis & 5 & 12.5 \\
\hline TOTAL & 40 & 100 \\
\hline
\end{tabular}

Table-III

Peroperative findings $(n=40)$.

\begin{tabular}{lcc}
\hline $\begin{array}{l}\text { Per-operative } \\
\text { Findings }\end{array}$ & Frequency & Percentage \\
\hline $\begin{array}{l}\text { Lumbar disc } \\
\text { herniation only }\end{array}$ & 35 & 87.5 \\
Spinal Stenosis & 5 & 12.5 \\
\hline TOTAL & 40 & 100 \\
\hline
\end{tabular}

Table IV

Validity of MRI findings compared to Per operative findings

\begin{tabular}{lccc}
\hline Pre-operative & \multicolumn{2}{c}{ Per-operative Findings } & Total \\
\cline { 2 - 4 } MRI Findings & $\begin{array}{c}\text { Lumbar disc } \\
\text { Herniation } \\
\text { only }\end{array}$ & $\begin{array}{c}\text { Spinal } \\
\text { Stenosis }\end{array}$ & \\
\hline Lumbar disc & $33(82.5 \%)$ & $02(5 \%)$ & $35(87.5 \%)$ \\
Herniation only & $(\mathrm{TP})$ & $(\mathrm{FP})$ & \\
Spinal Stenosis & $02(5 \%)$ & $03(7.5 \%)$ & $05(12.5 \%)$ \\
& $(\mathrm{FN})$ & $(\mathrm{TN})$ & \\
\hline Total & $35(87.5 \%)$ & $05(12.5 \%)$ & $40(100 \%)$ \\
\hline
\end{tabular}

$\mathrm{TP}=$ True positive, $\mathrm{FP}=$ False positive, $\mathrm{TN}=$ True negative, $\mathrm{FN}=$ False negative .

Table IV shows the validity of MRI findings compared to per-operative findings. The test results shows a Sensitivity of $94.28 \%$, Specificity of $60 \%$, Positive predictive value of $94.28 \%$, Negative predictive value of $60 \%$ and Accuracy of $90 \%$ in the diagnosis of lumbar disc herniation. Table-IV also shows that MRI detected herniated lumbar disc in $35(87.5 \%)$ cases of which $33(82.5 \%)$ was proved to have a herniated lumbar disc peroperatively. 

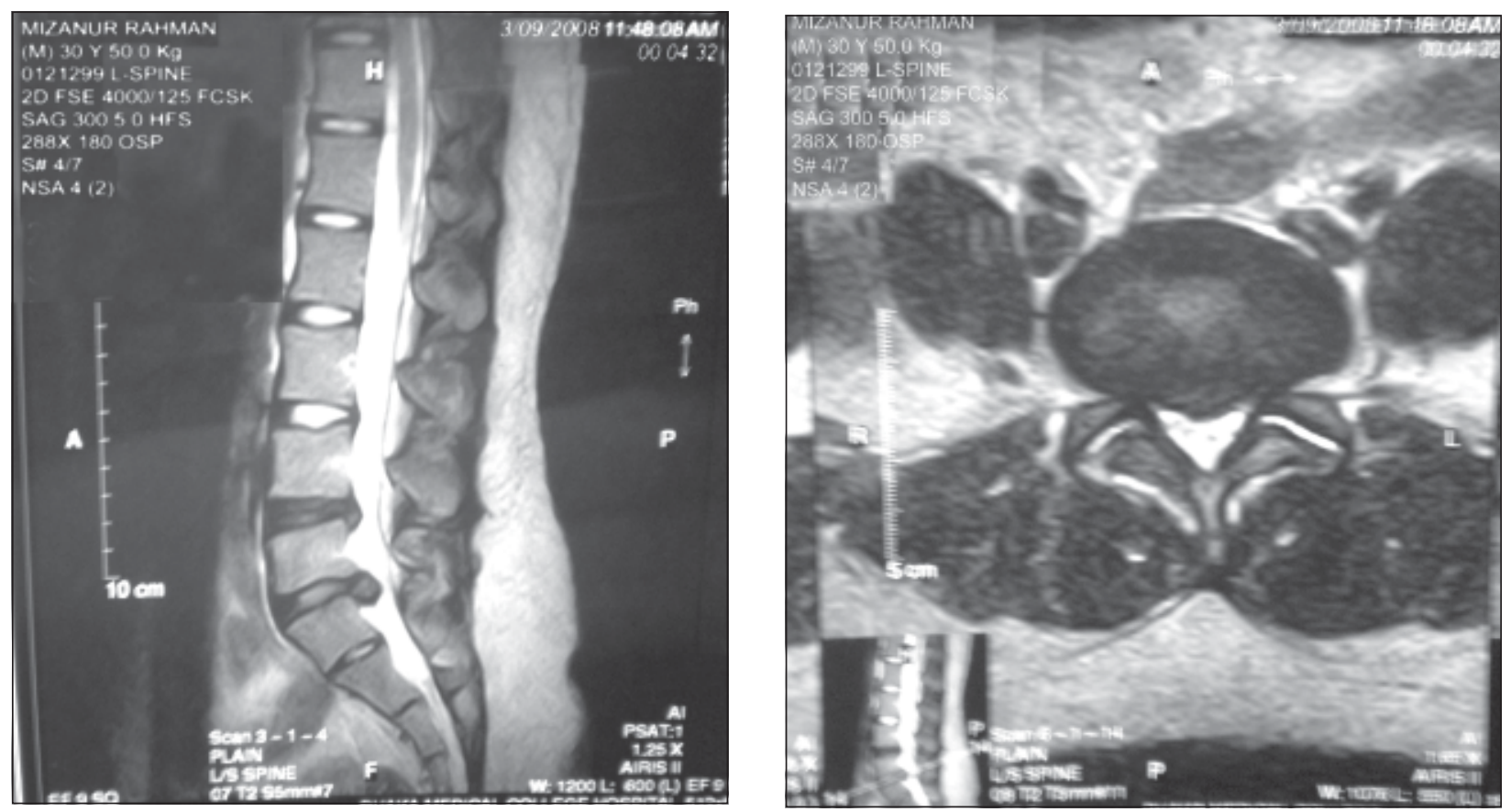

Sagittal T2-Weighted Image (T2WI) of Extruded lumbar disc at $\mathrm{L}_{5}-\mathrm{S}_{1}$ level (Left) with axial T2WI at the same level of the same patient
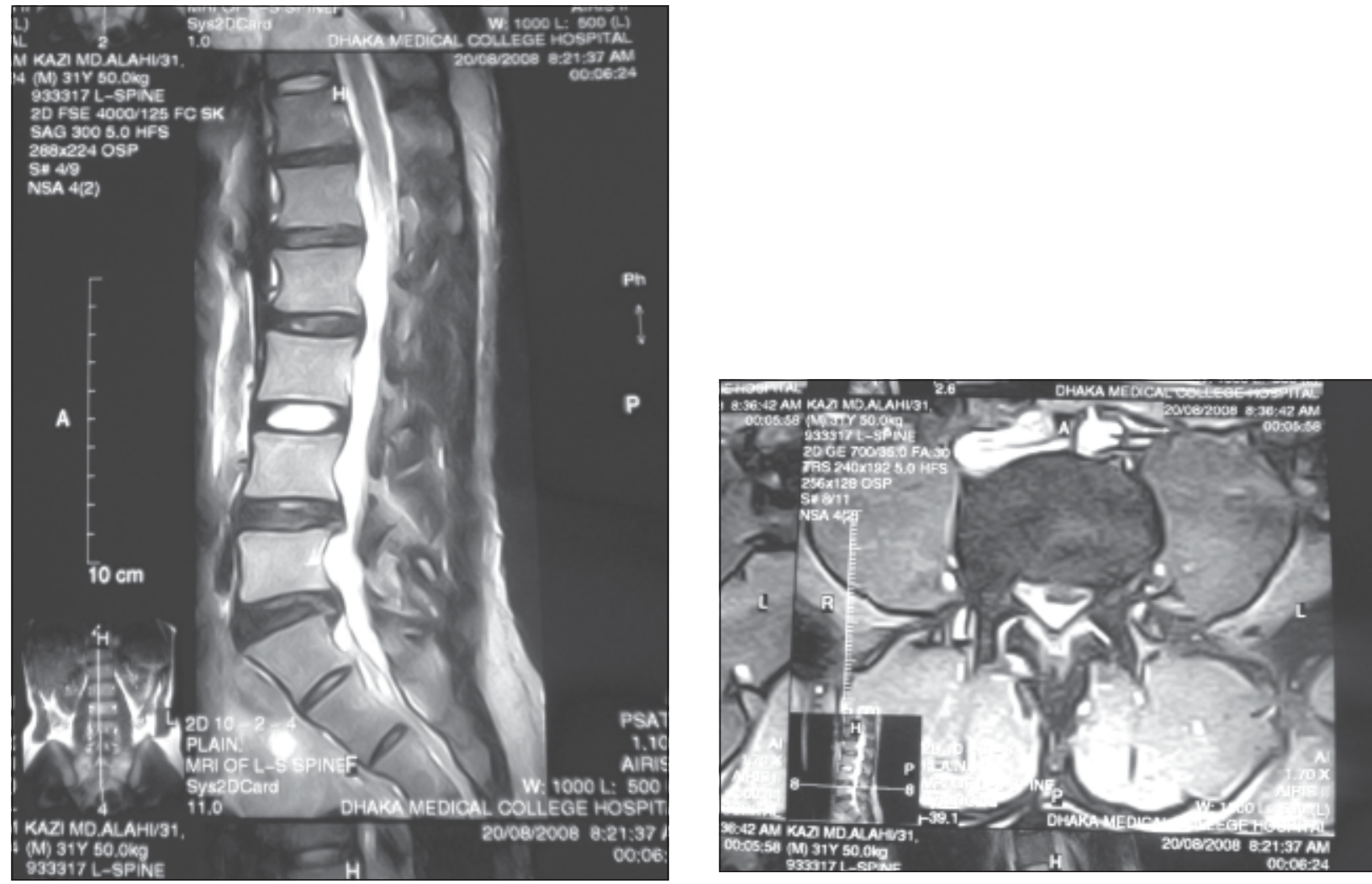

Sagittal T2WI of lumbar disc protrusion at $\mathrm{L}_{4-5} \& \mathrm{~L}_{5}-\mathrm{S}_{1}$ levels with spinal canal stenosis (Left) and Axial GE (Gradient Echo) image of lumbar disc protrusion at $\mathrm{L}_{4-5}$ level with spinal canal stenosis (Right) 

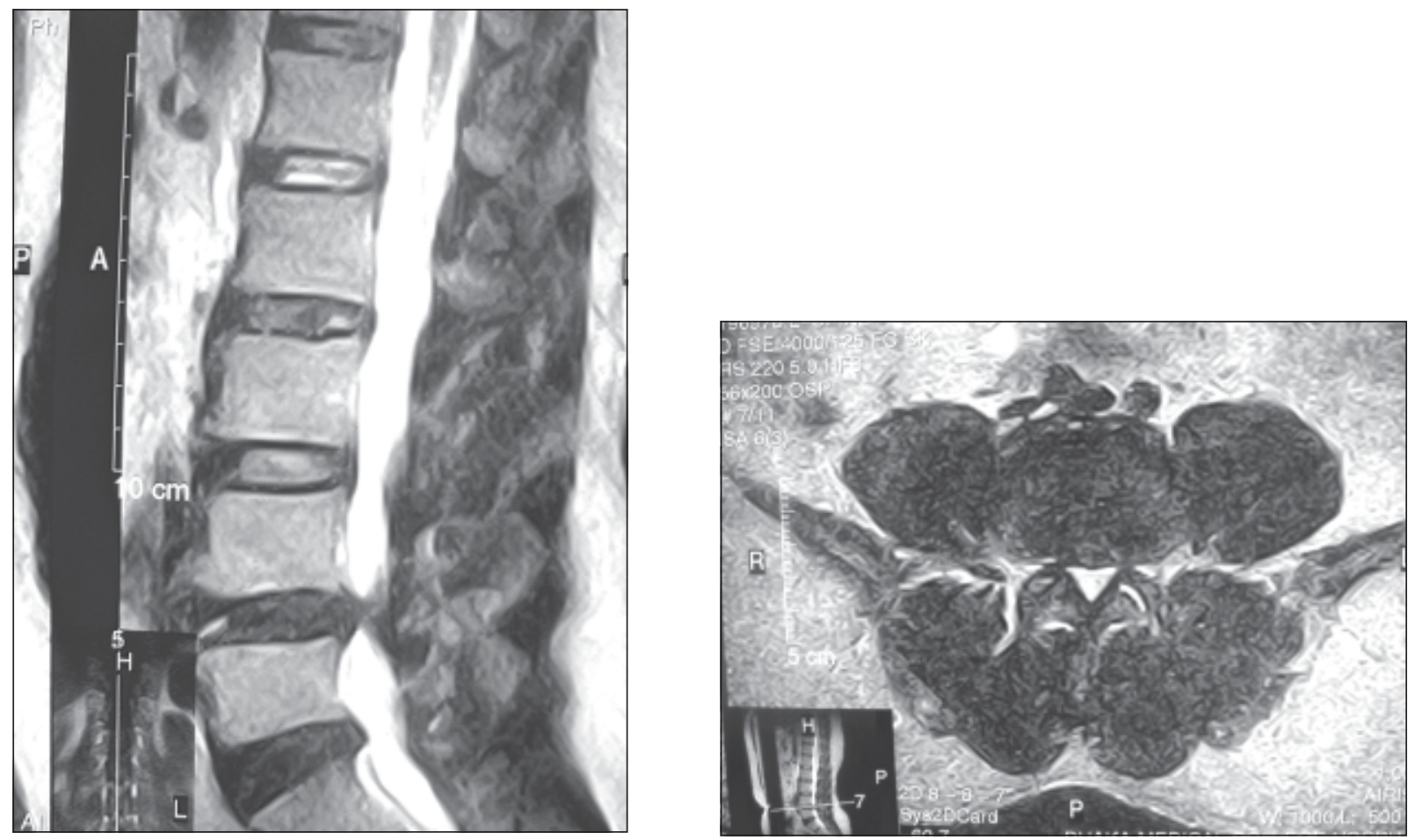

T2W Saggital(SAG) Image (Left) and T2W Axial image (Right) showing central and both paracentral disc protrusion causing anterior indentation to thecal sac at $\mathrm{L}_{4}-\mathrm{L}_{5}$ level with both lateral recess obliteration and compression over corresponding exiting nerve roots.
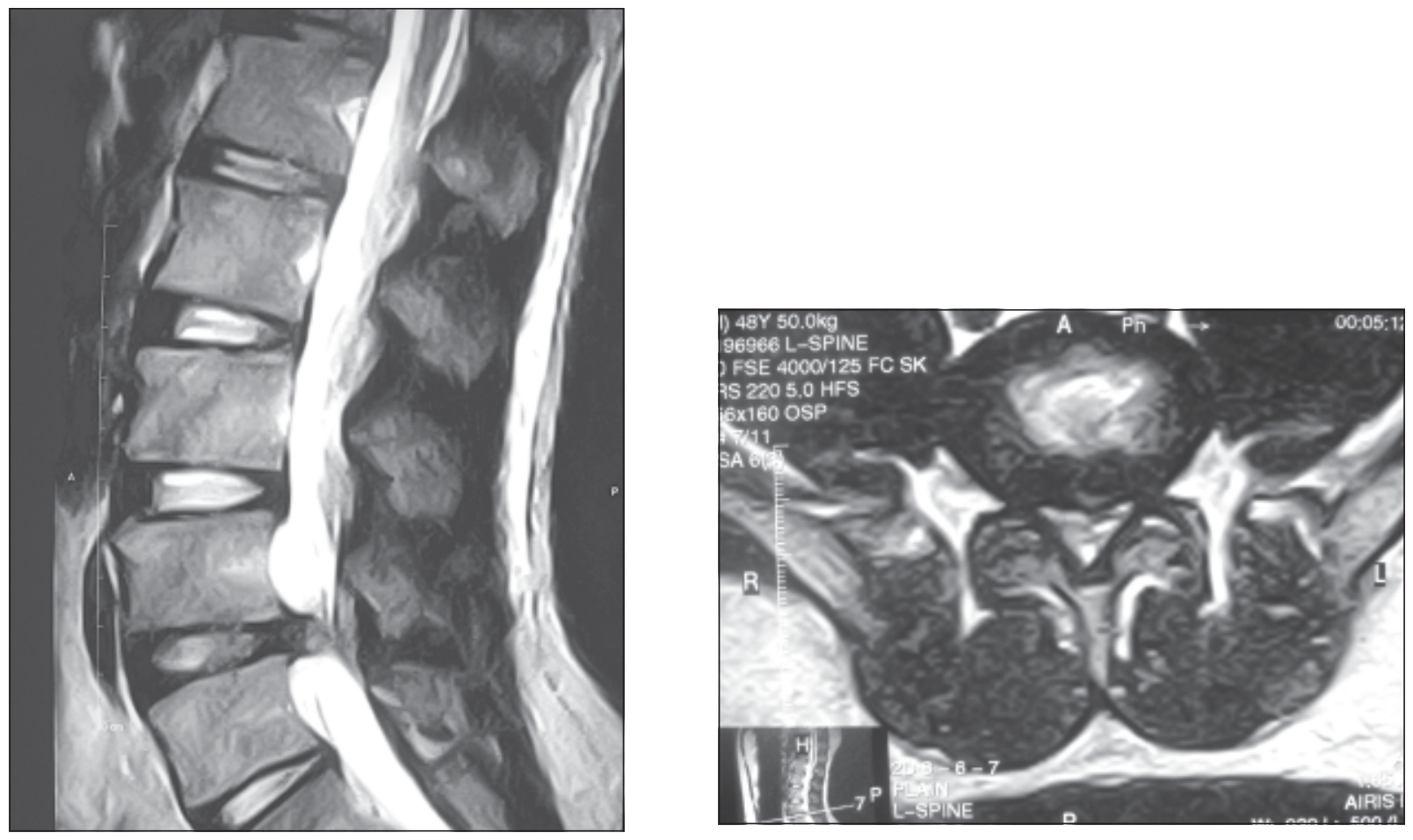

Severe spinal stenosis with bilateral neuronal foraminal narrowing resulting from central and both paracentral disc extrusion at the level of $\mathrm{L}_{4}-\mathrm{L}_{5}$ (Lower images in T2WI SAG \& Axial). 


\section{Discussion:}

40 patients who fulfilled the inclusion and exclusion criterion were included in the study during the period of January 2008 to March 2009.

Symptomatic lumbar disc herniation occurs most commonly in individuals between the ages 30 and 50 years $^{9}$. In our study $21(52.5 \%)$ cases are found in $3^{\text {rd }}$ decade, $17(42.5 \%)$ cases of $4^{\text {th }}$ decade and $02(5 \%)$ cases in $5^{\text {th }}$ decade.

One of the risk factors is male gender ${ }^{4}$. Findings of our study showed a male to female ratio of lumbar disc herniation is 2.33:1 (28:12)

Risk factors also include stressful occupation ${ }^{4}$ and sedentary occupation ${ }^{9}$. This study shows that $60 \%$ of the subjects had stressful occupation and that of $40 \%$ was sedentary.

Roy $\mathrm{SK}^{2}$ in his study found $68.57 \%$ of the patients had lumber disc prolapse at the L4-L5 level, $31.42 \%$ of the patients had lumber disc prolapse at L5-S1 level. Hossain MI ${ }^{10}$ in his analysis found that distribution of intervertebral disc lesions is most common at L5-S1 level (95\%) and very closely followed by L4-5 (92\%). In our study, Lumber disc herniation wasmostly seen at L4-5 level (57.5\%) and L5-S1 level (25\%).

Natural history of disc disease is one of recurrent episodes of low back pain and leg pain 11 . In the current study $100 \%$ patients presented with low back pain and $87.5 \%$ presented with pain radiating to lower limb.

In the study of Foristall RM ${ }^{12}$ accuracy of MRI was $90.3 \%$ and sensitivity was $91.7 \%$. Weiner and Patel ${ }^{13}$ showed that, MRI was $72 \%$ sensitive, $68 \%$ specific, and $70 \%$ accurate in detecting containment status of lumbar herniated discs. Current study showed almost a similar result which shows that MRI has $94.28 \%$ sensitivity, 60\% specificity and 90\% accuracy.

Modic MT ${ }^{5}$ showed at the operative levels, there was $82.6 \%$ agreement between MR and surgical findings for both type and location of disease. Our study reveals among the cases diagnosed as lumbar disc herniation, $82.5 \%$ were proved to be lumbar disc herniation during operation.

\section{Conclusion:}

40 cases of clinically suspected Lumbar disc herniation presented with low back pain were studied in Dhaka Medical College Hospital during the period of January 2008 to March 2009. The peak incidence was found to be in $3^{\text {rd }}$ decade, male female ratio was 2.33:1 with all the patients having the complaints of low back pain.

MRI detected herniated lumber disc in 35 $(87.5 \%)$ cases of which $33(82.5 \%)$ was proved of lumber disc herniation preoperatively. MRI diagnosed $05(12.5 \%)$ cases of spinal stenosis. 02 cases were finally diagnosed during surgery as lumber disc herniation ( $\mathrm{FN})$ and 03 cases spinal stenosis (TN). Number of false positive (FP) cases was 02. In our study MRI showed $94.28 \%$ sensitivity, 60\% specificity and 90\% accuracy.

This study established that the use of MRI as the radiological investigation for detection of lumbar disc herniation is safe and cost effective.

\section{References:}

1. Lebkowski WJ, Lebkowska U, Niedzwiecka M, Dzieciol J. The radiological symptoms of lumbar disc herniation and degenerative changes of lumbar intervertebral discs. Med Sci Monit, 2004;10 (suppl 3):112-114.

2. Roy SK, Treatment of Prolaspsed lumbar Intervetebral disc by minimally invasive open lumbar discectomy, [MS Thesis]. Dhaka: BSMMU; 2005.

3. Fardon DF, Milette PC, Nomenclature and classification of lumbar disc pathology: Recommendations of the combined task forces of North American Spine Society, American Society of Spine Radiology, American Society of neuroradiology-SPINE. 2001; 26(5): E-93-E-113.

4. Williams NS, Bulstrode CJk, O' Connell PR, Bailey and Love's Short Practice of surgery,25th edn, London: Hodder Arnold; 2008: p. 476-7.

5. Modic, MT, Masaryk T, Boumphrey F, Goormastic M, Bell G, Lumbar herniated disk Disease and Canal Stenosis Prospective Evaluation by surface Coil MR, CT, and Myelography, AJR. 1986; 147: 757-65.

6. van Rijn JC, Klemetso N, Reitsma, JB, Majoie CBLM, Hulsmans FJ, Peul WC et al. Observer 
Variation in MRI Evaluation of Patients Suspected of Lumbar Disc Herniation. AJR. 2005; 184: 299303.

7. Ross J ,Brant zawadzki M, Moore K, Chen M , Salzman K, Diagnostic Imaging: Spine. Elsevier, Saunders; 2004. p. 34-5, 60-1.

8. Atlas, SW, Magnetic Resonance Imaging of the Brain and Spine. Vol-2 3rd edn, Philadelphia: Lippincott Williams \& Wilkins; 2002: p. 1642-7, 1656-66.

9. Lumbar Disc Disease: The Natural History: Lumbar Disease and Low- Back Pain' Neurosurg Focus, 2002,13 (2)http://www.medscape. com/ view article/442526
10. Hossain MI, Role of MRI in Evaluation of low back pain: a study of 100 cases. [FCPS Dissertation]. Dhaka: BCPS; 2003.

11. Canale ST. Campbell's Operative Orthopedics, Vol. 2 10th ed. Mosby; 2003: p. 1957-2028.

12. Forristal RM, Marsh HO, Pay NT. Magnetic resonance imaging and contrast $\mathrm{CT}$ of the lumbar spine. Comparison of diagnostic methods and correlation with surgical findings, Spine1988; 13(9): 1049-54.

13. Weiner BK, Patel R. The accuracy of MRI in the detection of Lumbar Disc Containment. J Ortho Surg Res. 2008; 3(46): 46. 